\title{
Relationship between Body Fat Percentages by Bioelectrical Impedance Analysis and Body Mass Index (BMI) And other metabolic Parameters among Filipino Adults At Emilio Aguinaldo College Medical Center- Cavite
}

\author{
Yadav $\mathrm{J}^{1}$, Sherwin $\mathrm{E}^{1}$, Baris $\mathrm{M}^{1}$, Pagsisihan $\mathrm{D}^{2}$, Baston $\mathrm{A}^{3}$, Sembrano $\mathrm{JM}^{4}$ \\ ${ }^{1}$ Department of Internal Medicine, ${ }^{2}$ Endocrinologist, ${ }^{3}$ Nephrologist, ${ }^{4}$ Cardiologist and Head of \\ Department, Emilio Aguinaldo College of Medical Center, Cavite, Phillipines
}

\begin{abstract}
Background: Obesity posing burgeoning risk for mortality, diabetes mellitus, cardiovascular diseases and cancer among fast ageing Filipino population must be accurately measured by the use of rapid, noninvasive, digitally precise tool, Body Fat percentage and segmental body composition obesity predictors in Bioelectrical Impedance Analysis where overseas studies established significant but limited results. Our study focused on Filipino group with the correlation of its body fat percentage and other obesity predictors set in BIA therein like Free Fat Mass, Fat, Bone and Muscle masses, visceral fat amongst others, with Body Mass Index and other conventional obesity measurements. Method: This cross-sectional, correlational study included 363 Filipinos, patients and employees of Emilio Aguinaldo College Medical CenterCavite and nearby health center, 18-80 years of age, BMI of 16-34, excluded those pregnant and bearing metallic body implants, have imparted their History, level of activity. Installed Standardized protocol for Physical Examination, measurements of height, weight, Body mass index waist and hip circumferences, waist-hip ratio, systolic blood pressure and diastolic blood pressure. Results: All BIA measurements used Tanita MC980. The Pearson correlation coefficients, Binary logistic regression analysis, two tailed test, Shapiro-Wilk tests analyzed 137 Males, 226 females with mean age of 34.64, p-value of 0.29, showed strong, significant correlation between BFP and BMI, and other measurements, where BMI had strongest correlation to women than men with synonymous correlation with other metabolic variables and predictors, and no significant difference between genders. Conclusion: Our research reflected that Body Fat Percentage have strong significant correlation with BMI, metabolic variables and obesity predictors measured, established a better estimate for obesity as compared to the conventional measurements.
\end{abstract}

Keywords: Bioelectrical Impedance Analysis, Percent Body Fat, Metabolic variables

\section{Indroduction:}

Obesity is defined as body mass index (BMI) 30 $\mathrm{kg} / \mathrm{m} 2$ or more which is obtained by dividing a person's weight by the square of the person's height, has emerged as one of the most common health concern in the world. In Asia, approximately $17 \%$

\section{Correspondence Author}

Dr. Jitendra Kumar Yadav, Department of Internal Medicine Emilio Aguinaldo College of Medical Center, Cavite Phillipines.

Email ID: of population is considered obese by World Health Organization (WHO $)^{1}$. In the Philippines, the prevalence of obesity on 2003 was $4.9 \%$ by body mass index (BMI), and $10.2 \%$ and $65.6 \%$ by waisthip ratio (WHR) in men and women respectively. ${ }^{2}$

Obesity is associated with an increased risk of mortality ${ }^{3}$, type 2 diabetes ${ }^{4}$, cardiovascular diseases and cancer ${ }^{5}$. Moreover, obese individuals have 7 times higher the risk of developing diabetes than individuals of a normal $\mathrm{BMI}^{6}$. Since obesity is 
increased with advancing age, the on-going rapid aging of the population will further impose a greater burden on the society. Indeed, it has been estimated that by 2030 nearly one-third of the world population is overweight or obese ${ }^{7}$.

Bioelectrical Impedance Analysis (BIA) is known to provide a rapid, non-invasive and relatively accurate measurement of body composition with the possibility of utilizing at field settings. At present, there are studies conducted in various ethnic groups in other countries to determine the effect of age and gender in the Body Mass Index (BMI) - Body Fat Percentage (BMI-BF\%) relationship, and there are uncertainties about the final conclusion. At present, relationship between Body Mass Index (BMI) and Body Fat Percentage estimated By Bioelectrical Impedance is not widely known in Philippines.

The objective of this study is to determine the relationship between Body Fat Percentage estimated By Bioelectrical Impedance and Body Mass Index (BMI) among Groups of Filipino Adults in Emilio Aguinaldo Medical Center.

\section{Methods:}

This is a cross-sectional analytic study that will include Filipino adult patients and individuals in Emilio Aguinaldo Medical center for a duration of 6 months. A cross sectional study to be conducted where height, weight and body composition measurements of adult patients will be carried out by a group of medical graduates.

The study was approved and reviewed by the EACMCC Medical Research Technical Review Committee (EMRTRC) and submitted to DLSHI C Independent Ethics Board (DLSHI-IEC) Panel for ethics review and approval. The study was conducted only upon approval from Panel.

The Inclusion Criteria was to include adult Filipino patients' age 18-80 years old with BMI $16-34 \mathrm{~kg} /$ $\mathrm{m} 2$ in this study. Subjects who were having metallic implants in the body like cardiac pacemaker, metallic prosthetics were excluded. Pregnant women were likewise excluded.

$\mathrm{BF} \%$ will be estimated from bioelectrical impedance analysis. Pearson's' correlation coefficient(r) will be used to calculate and to see the relationship between $\mathrm{BMI}-\mathrm{BF} \%$ in the different age groups. Multiple regression analysis will be performed to determine the effect of age and gender in the relationship and polynomial regression will be carried out to see its' linearity.

\section{Results:}

The Table 1.0 showed that a total of 363 subjects were included in the analysis, Males with 137 subjects and females with 226 subjects, with a mean age of 34.64 and p-value of 0.29 .

\subsubsection{Table 1. Demographic and clinical characteristics of the study participants}

\begin{tabular}{|c|c|c|c|c|}
\hline & Total $(n=363)$ & Male $(n=137)$ & Female $(\mathrm{n}=226)$ & P-value \\
\hline & \multicolumn{3}{|c|}{ Frequency $(\%) ;$ Mean + SD; Median (IQR) } & \\
\hline Age & $34.64+12.47$ & $35.53+12.0$ & $34.10+12.74$ & 0.292 \\
\hline Weight $(\mathrm{kg})$ & $63.64+14.0$ & $72.12+12.93$ & $58.49+11.99$ & $<0.001$ \\
\hline Height (m) & $1.60+0.09$ & $1.68+0.08$ & $1.55+0.06$ & $<0.001$ \\
\hline BMI & $24.67+4.43$ & $25.59+4.16$ & $24.12+4.51$ & 0.002 \\
\hline Obese & $67(18.46)$ & $29(21.17)$ & $38(16.81)$ & 0.300 \\
\hline Body fat $\%$ & $29.86+8.94$ & $22.67+6.51$ & $34.22+7.24$ & $<0.001$ \\
\hline FFM (Fat free mass) & $41(36.6-52.6)$ & $55.2(51.2-59.5)$ & $37.3(34.9-40.1)$ & $<0.001$ \\
\hline
\end{tabular}




\begin{tabular}{|l|l|l|l|l|}
\hline Fat mass $(\mathrm{kg})$ & $17.6(13.3-23.4)$ & $15.5(11.9-20.3)$ & $19.05(15-24.3)$ & $<0.001$ \\
\hline Bone mass $(\mathrm{kg})$ & $2.4(2-2.8)$ & $2.9(2.7-3.1)$ & $2.1(1.9-2.3)$ & $<0.001$ \\
\hline Muscle mass & $38.6(24.6-49.9)$ & $52.3(48.5-56.4)$ & $35.2(33-37.8)$ & $<0.001$ \\
\hline Protein $(\mathrm{kg})$ & $9.1(8.1-13.9)$ & $15.5(13.2-17.2)$ & $8.3(7.5-9)$ & $<0.001$ \\
\hline ECW $(\mathrm{kg})$ & $12.4(10.9-14.6)$ & $14.7(13.8-15.8)$ & $11.4(10.1-12.4)$ & $<0.001$ \\
\hline ICW $(\mathrm{kg})$ & $17.2(15-21.1)$ & $22.1(20-23.7)$ & $15.7(14.2-17.2)$ & $<0.001$ \\
\hline BMR KJ & $5234(4632-6272)$ & $6523(5870-7079)$ & $4780(4464-5201)$ & $<0.001$ \\
\hline BMR kcal & $1251(1107-1499)$ & $1559(1403-1692)$ & $1142.5(1067-1243)$ & $<0.001$ \\
\hline Visceral fat & $7(4-10)$ & $10(8-13)$ & $5(3-8)$ & $<0.001$ \\
\hline TBW (kg) & $29.5(25.9-35.4)$ & $36.8(33.9-39.3)$ & $26.75(24.5-29.4)$ & $<0.001$ \\
\hline TBW \% & $48.7(45.7-51.7)$ & $51.3(48-55.3)$ & $47.4(44.3-49.9)$ & $<0.001$ \\
\hline ECW/TBW\% & $41.3(39.8-42.7)$ & $40.3(39.2-41.6)$ & $41.8(40.4-43.6)$ & $<0.001$ \\
\hline Waist circ. & $85(77-93.7)$ & $90(81-97)$ & $82(75-91)$ & $<0.001$ \\
\hline Hip circ. & $95(89.4-102)$ & $97(91-104)$ & $94(88-100)$ & $<0.001$ \\
\hline Waist-hip-ratio & $0.9(0.86-0.93$ & $0.92(0.89-0.95)$ & $0.89(0.83-92)$ & $<0.001$ \\
\hline Systolic blood pressure & $119.12+15.13$ & $124.89+14.76$ & $115.62+14.29$ & $<0.001$ \\
\hline Diastolic blood pressure & $80.41+11.48$ & $84.60+11.82$ & $77.87+10.52$ & $<0.001$ \\
\hline METS & & & & $18(7.96)$ \\
\hline 7 to 10 & $35(9.64)$ & $17(12.41)$ & $208(92.04)$ & 0.164 \\
\hline$>10$ & $328(90.36)$ & $120(87.59)$ & & \\
\hline
\end{tabular}

Abbreviations: METS (metabolic equivalents), ECW(extracellular water), ICW(intracellular water), TBW (total body water), BMR (basal metabolic rate), BMI (body mass index)

The mean Body Fat percentage (BF\%) was 29.86 +8.94 , with higher value for women at $34.22+$ 7.24 as compared to $22.67+6.51$ for men, has no significant difference. The Waist Circumference has mean value of 85 (77-93.7), higher with males at $90(81-97)$ as compared with females at 82 (75-91) with no significant difference. The Hip Circumference has mean value of 95 (89.4-102), higher with males at $97(91-104)$ as compared with females at 94 (88-100), which has no significant difference. Waist-Hip Ratio mean value is 0.9 (0.86-0.93, with no significant difference between male and females.
1.1.2 Table 2.0 Correlation coefficient of Body fat percentage, WC, WHR, and Blood pressure to BMI

\begin{tabular}{|l|l|l|l|}
\hline & Total & Male & Female \\
\hline Body fat percentage & 0.6133 & 0.8959 & 0.9457 \\
\hline Waist circumference & 0.7312 & 0.7537 & 0.7088 \\
\hline Waist-hip-ratio & 0.4494 & 0.5180 & 0.3771 \\
\hline $\begin{array}{l}\text { Systolic blood } \\
\text { pressure }\end{array}$ & 0.3940 & 0.3463 & 0.3802 \\
\hline $\begin{array}{l}\text { Diastolic blood } \\
\text { pressure }\end{array}$ & 0.4294 & 0.3883 & 0.4169 \\
\hline $\begin{array}{l}\text { All P-value were } \\
<0.001\end{array}$ & & & \\
\hline
\end{tabular}

The Table 2.0 showed the correlation of BMI to $\mathrm{BF} \%$ which is higher in females $(r=0.9457)$ 
as compared to Males ( $\mathrm{r}=0.8959$. There is higher correlation of Body fat percentage to BMI ( $\mathrm{r}=0.6133)$ as compared to, Waist-hip ratio( $\mathrm{r}=0.44)$, and to systolic $(\mathrm{r}=0.39)$ and diastolic $\mathrm{BP}(\mathrm{r}=0.42)$ but lower as compared to waist circumference $(\mathrm{r}=0.73)$.

\subsubsection{Table 3.0 Correlation coefficient of BMI, WC, WHR, and Blood pressure to Body fat percentage}

\begin{tabular}{|l|l|l|l|}
\hline & Total & Male & Female \\
\hline Body mass index & $0.6133^{*}$ & $0.8959^{*}$ & $0.9457^{*}$ \\
\hline Waist circumference & $0.3356^{*}$ & $0.6888^{*}$ & $0.6857^{*}$ \\
\hline Waist-hip-ratio & 0.0841 & $0.4719^{*}$ & $0.3542^{*}$ \\
\hline Systolic blood pressure & 0.0702 & $0.3013^{*}$ & $0.3707^{*}$ \\
\hline Diastolic blood pressure & 0.0874 & $0.2904^{*}$ & $0.3994^{*}$ \\
\hline
\end{tabular}

* - P-value $=<0.001$

The Table 3.0 showed the correlation of Body Fat Percentage (BF \%) to BMI, WC, WHR and Blood Pressure. The correlation is more significant with BMI $(\mathrm{r}=0.61)$ as compared to WC $(\mathrm{r}=0.33)$, WHR $(\mathrm{r}=0.08)$ and Systolic Blood Pressure $(\mathrm{r}=0.07)$ and diastolic BP $(\mathrm{r}=0.08)$.

\subsubsection{Table 4.0 Predictors of obesity}

\begin{tabular}{|l|c|c|c|}
\hline & Crude odds ratio & 95\% CI & P-value \\
\hline Age & 0.9992 & 0.9781 to 1.0276 & 0.941 \\
\hline Weight $(\mathrm{kg})$ & 1.2144 & 1.1604 to 1.2710 & $<0.001$ \\
\hline Height $(\mathrm{m})$ & 4.6888 & 0.2715 to 80.9862 & 0.288 \\
\hline Body fat percentage & 1.2211 & 1.1614 to 1.2840 & $<0.001$ \\
\hline FFM & 1.0786 & 1.0496 to 1.1083 & $<0.001$ \\
\hline Fat mass $(\mathrm{kg})$ & 1.6777 & 1.4567 to 1.9322 & $<0.001$ \\
\hline Bone mass $(\mathrm{kg})$ & 9.8700 & 5.0534 to 19.2776 & $<0.001$ \\
\hline Muscle mass & 1.0808 & 1.0505 to 1.1119 & $<0.001$ \\
\hline Protein $(\mathrm{kg})$ & 1.0279 & 0.9635 to 1.0966 & 0.405 \\
\hline ECW $(\mathrm{kg})$ & 2.0786 & 1.7229 to 2.4984 & $<0.001$ \\
\hline ICW $(\mathrm{kg})$ & 1.2466 & 1.1618 to 1.3377 & $<0.001$ \\
\hline BMR KJ & 1.0010 & 1.0001 to 1.0013 & $<0.001$ \\
\hline BMR kcal & 1.0043 & 1.0032 to 1.0055 & $<0.001$ \\
\hline Visceral fat & 1.6639 & 1.4777 to 1.8735 & $<0.001$ \\
\hline TBW kg) & 1.2017 & 1.1418 to 1.2648 & $<0.001$ \\
\hline TBW \% & 0.6862 & 0.6234 to 0.7552 & $<0.001$ \\
\hline ECW/TBW\% & 1.2320 & 1.0957 to 1.3853 & $<0.001$ \\
\hline Waist circumference & 1.2003 & 1.1483 to 1.2546 & $<0.001$ \\
\hline Hip circumference & 1.2151 & 1.1577 to 1.2753 & $<0.001$ \\
\hline Waist-hip-ratio & 3254559 & 15615 to $6.78 \times 108$ & $<0.001$ \\
\hline Systolic blood pressure & 1.0486 & 1.0288 to 1.0688 & $<0.001$ \\
\hline Diastolic blood pressure & 1.0711 & 0.1583 to 0.7026 & 0.004 \\
\hline METS $>10$ & 0.3335 & & \\
\hline
\end{tabular}


Relationship between Body Fat Percentages by Bioelectrical Jour of Diab and Endo Assoc of Nepal 2021; 5 (2): (26-32) ISSN Print 2594-3367 ISSN Online 2631-2107
Abbreviations: METS (metabolic equivalents), ECW(extracellular water), ICW(intracellular water), TBW (total body water), BMR (basal metabolic rate), BMI (body mass index), FFM(fat free mass)

Weight: for every $\mathrm{kg}$ increase in weight, the odds of being obese also increases by $21.44 \%, \mathbf{B F} \%$ : for every percentage increase in body fat, the odds of being obese also increases by $22.11 \%$, FFM: for every unit increase in FFM, the odds of being obese also increases by $7.86 \%$, Fat mass: for every $\mathrm{kg}$ increase in fat mas, the odds of being obese also increases by $67.77 \%$, Bone mass: for every $\mathrm{kg}$ increase in bone mass, the odds of being obese also increases by 9.87 times., ECW: for every $\mathrm{kg}$ increase in $\mathrm{ECW}$, the odds of being obese also increases by $107.86 \%$, ICW: for every $\mathrm{kg}$ increase in ICW, the odds of being obese also increases by $24.66 \%$, BMR KJ: for every unit increase in BMR KJ, the odds of being obese also increases by $0.10 \%$, BMR KJ: for every unit increase in BMR kcal, the odds of being obese also increases by $0.43 \%$, Visceral fat: for every unit increase in visceral fat, the odds of being obese also increases by $66.39 \%$, TBW: for every $\mathrm{kg}$ increase in TBW, the odds of being obese also increases by $20.17 \%$, TBW\%: for every percentage increase in TBW, the odds of being obese also decreases by $31.38 \%$, ECW/TBW\%: for every percentage increase in ECW/TBW, the odds of being obese also increases by $23.20 \%$, WC: for every $\mathrm{cm}$ increase in waist circumference, the odds of being obese also increases by $20.03 \%$, HC: for every $\mathrm{cm}$ increase in hip circumference, the odds of being obese also increases by $21.51 \%$, WHR: for every unit increase in waist-hip-ratio, the odds of being obese also increases by over 3 million folds., SBP: for every unit increase in SBP, the odds of being obese also increases by $4.86 \%$, DBP: for every unit increase in DBP, the odds of being obese also increases by $7.11 \%$

\section{Discussion:}

In this study, we analyzed the correlation between BFP measured by BIA, with BMI and other anthropometric and metabolic variables in 363 patients at Emilio Aguinaldo College Medical Center-Cavite. The results of our study showed that BFP has a significant correlation with BMI and other anthropometric variables (WC and WHR). However simple anthropometric measurements (WC, and WHR) had also better correlation with BMI. We limited the inclusion criteria to subjects with age 18-80 years old. Changes in body composition occur as part of the normal aging process. In elderly, the amount of lean body mass decreases with age, a process called sarcopenia. Data from the Rosetta Study show that older adults have, on average, more fat than younger adults at any given $\mathrm{BMI}^{8}$. The predictive equations which may have been derived in populations of younger ages, might be less valid in elderly individuals ${ }^{9}$. Hence, we included the subjects with maximum age of 80 year-old.

We only included patients with BMI $16-34 \mathrm{~kg} /$ $\mathrm{m} 2$ in this study. Clinical use of BIA in subjects at extremes BMI ranges cannot be recommended for routine assessment and it should be interpreted with caution. BIA results are affected by tissue hydration in severely malnourished patients. The overall effect of severely obese state is overestimation of fat-free mass, and thus an underestimation of BFP(10). The result of current study demonstrated that BFP had strong and significant correlation with BMI ( $\mathrm{r}=0.902$ for men; $\mathrm{r}=0.933$ for women) and $\mathrm{WC}(\mathrm{r}=0.822$ for men; $\mathrm{r}=0.787$ for women) among adult Filipino(11). Among the three anthropometric measurements (BMI, WC, and WHR), BMI had the strongest correlation with PBF. In addition, it is noteworthy that these degrees of correlation differed between the sexes. This agrees with the study by Kobayashi et al., who demonstrated the strong correlation of BFP and BMI among Japanese population ( $\mathrm{r}=0.813$ for men; $\mathrm{r}=0.888$ for women). On the other hand, a previous study by Ozenoglu et al showed only moderately strong correlation between PBF with BMI $(\mathrm{r}=0.584)$ \& WC $(\mathrm{r}=0.598)$ among female subjects(12). Study by Lemos-Santos et al (12)., PBF was less correlated with WHR $(\mathrm{r}=0.55)$ compared with $\mathrm{WC}(\mathrm{r}=0.90)$ among Brazilian men (13). We use Binary logistic regression analysis 
was used to determine the significant predictors of obesity among study participants. Our findings showed significant correlation between BFP and BMI.

A major limitation of this study is Subjects who were having metallic implants in the body like cardiac pacemaker, metallic prosthetics were excluded. Pregnant women were likewise excluded. They could be classified as having metabolic syndrome. Exclusion of these subjects may cause underestimation of the PBF measurement ability.

\section{Conclusion:}

The Body Fat Percentage (BFP) measured by BIA has a strong and significant correlation with the BMI, the other anthropometric measurements like Waist and Hip Circumference and its ratio, the metabolic variables like systolic and diastolic blood pressure, and those that are useful for predicting obesity measured by BIA like Free Fat Mass, Fat mass $(\mathrm{kg})$ Bone mass $(\mathrm{kg})$ Muscle mass Protein $(\mathrm{kg})$ ECW (kg) ICW (kg) BMR KJ BMR kcal Visceral fat TBW (kg) TBW \% ECW/TBW\%.

With the principles set in the Bioelectrical Impedance Analysis, where electric current passes through the body at a differential rate depending on body compositions of water and different ions measures digitally at Ionic level, we can therefore conclude that Body Fat Percentage measured by BIA is an better gauge of level of Obesity as compared to manual BMI using height and weight, and other anthropometric measurements like waist and hip circumference.

\section{Recommendations:}

This study recommends the use of BIA (Tanita MC980) as an epidemiological tool for the assessment of obesity in the different age groups and subgroups of metabolically challenged age groups.

\section{References:}

1. Dr Chizuru Nishida, Department of Nutrition for Health and Development, WHO, Appropriate body-mass index for Asian populations and its implications for policy and intervention strategies

2. Filipinos Katherine, M.D, Roberto C. Mirasol, M.D., Kevin Carl Santos. Correlation of Percent Body Fat by Bioelectrical Impedance Analysis with Anthropometric and Metabolic Variables Among Adult. Lancet 2004; 363(9403):15763. PMID: 14726171

3. WHO Expert Consultation. Appropriate body-mass index for Asian populations and its implications for policy and intervention strategies .Lancet 2004; 363(9403):157-63. PMID: 14726171

4. Sy RG, Morales DD, Dans AL, et al. Prevalence of atherosclerosis related risk factors and diseases in the Philippines. $\mathrm{J}$ Epidemiol. 22(5):440-447, 2012.

5. Whitlock G, Lewington S, Sherliker P, Clarke $\mathrm{R}$, Emberson J, Halsey J, et al. Body-mass index and cause- specific mortality in 900,000 adults: collaborative analyses of 57 prospective studies. Lancet 2009; 373(9669):1083-96. doi: 10.1016/S0140- 6736(09)60318-4 PMID: 19299006

6. Kodama S, Horikawa C, Fujihara K, Heianza Y, Hirasawa R, Yachi Y, et al. Comparisons of the strength of associations with future type 2 diabetes risk among anthropometric obesity indicators, including waist-to-height ratio: a meta-analysis. Am J Epidemiol 2012; 176(11):959-69. doi: 10.1093/aje/kws172 PMID: 23144362

7. Bray GA. Medical consequences of obesity. J Clin Endocrinol Metab 2004; 89(6):2583-9. PMID: 15181027

8. Ketherine, Mirasol, RC., Santos KC: Correlation of Percent Body Fat by Bioelectrical Impedance Analysis with Anthropometric and Metabolic Variables Among Adult Filipinos. Phil J Internal Med, 2016,April-May, Volume 54 Number 2 
9. Roubenoff R, Hughes VA. Sarcopenia: current concepts. J Gerontol A Biol Sci Med Sci. 55(12):716-724, 2000.

10. Gallagher D, Visser M, Sepulveda D, Pierson RN, Harris T, Heymsfield SB. How useful is body mass index for comparison of body fatness across age, sex, and ethnic groups?. Am J Epidemiol. 143(3):228-239, 1996.

11. Kobayashi J, Murano S, Kawamura I, et al. The relationship of percent body fat by bioelectrical impedance analysis with blood pressure, and glucose and lipid parameters. J Atheroscler Thromb. 13(5):221-226, 2006.
12. Ozenoglu A, Ugurlu S, Can G, Sarkis C, Demirel Y. Differences in the body composition and biochemistry in women grouped as normalweight, overweight, and obese according to body mass index and their relation with cardiometabolic risk. Cent Eur. J Med. 5(6):724-732, 2010.

13. Lemos-Santos MGF, Valente JG, GoncalvesSilva RMV, Sichieri R. Waist circumference and waist-to-hip ratio as predictors of serum concentration of lipids in Brazilian men. Nutrition. 20(10):857-862, 2004. 